\title{
The position of yeast snoRNA-coding regions within host introns is essential for their biosynthesis and for efficient splicing of the host pre-mRNA
}

\author{
SARA VINCENTI, ${ }^{1}$ VALENTINA DE CHIARA, ${ }^{1}$ IRENE BOZZONII, ${ }^{2}$ and CARLO PRESUTTI ${ }^{1}$ \\ ${ }^{1}$ Laboratory of Functional Genomics and Proteomics of Model Systems, Department of Genetics and Molecular Biology, \\ University "La Sapienza," Moro 5, 00185 Rome, Italy \\ ${ }^{2}$ Istituto Pasteur-Fondazione Cenci Bolognetti and IBPM-CNR, University "La Sapienza," Moro 5, 00185 Rome, Italy
}

\begin{abstract}
Genomic location of sequences encoding small nucleolar RNAs (snoRNAs) is peculiar in all eukaryotes from yeast to mammals: most of them are encoded within the introns of host genes. In Saccharomyces cerevisiae, seven snoRNAs show this location. In this work we demonstrate that the position of snoRNA-coding regions with respect to splicing consensus sequences is critical: yeast strains expressing mutant constructs containing shorter or longer spacers (the regions between snoRNA ends and intron splice sites) show a drop in accumulation of U24 and U18 snoRNAs. Further mutational analysis demonstrates that altering the distance between the $3^{\prime}$ end of the snoRNA and the branch point is the most important constraint for snoRNA biosynthesis, and that stable external stems, which are sometimes present in introns containing snoRNAs, can overcome the positional effect. Surprisingly enough, splicing of the host introns is clearly affected in most of these constructs indicating that, at least in $S$. cerevisiae, an incorrect location of snoRNA-coding sequences within the host intron is detrimental to the splicing process. This is different with respect to what was demonstrated in mammals, where the activity of the splicing machinery seems to be dominant with respect to the assembly of snoRNPs, and it is not affected by the location of snoRNA sequences. We also show that intronic box C/D snoRNA recognition and assembly of snoRNPs occur during transcription when splicing sequences are recognized.
\end{abstract}

Keywords: RNA processing; snoRNA; splicing; yeast

\section{INTRODUCTION}

All eukaryotic cells contain a large number of small ribonucleoprotein particles (snoRNPs) active in rRNA processing and modification and in ribosome assembly. These particles are formed by a single small nucleolar RNA (snoRNA) and a set of proteins. SnoRNAs (and snoRNPs) can be of two different classes: "box C/D," containing conserved sequences named boxes $\mathrm{C}$ and $\mathrm{D}$; and "box H/ACA," again containing conserved sequences with those names (Tollervey and Kiss 1997; Kiss 2001). Different proteins bind the two classes forming the ribonucleic particle snoRNPs. SnoRNPs, more specifically the snoRNA

Reprint requests to: Carlo Presutti, Laboratory of Functional Genomics and Proteomics of Model Systems, Department of Genetics and Molecular Biology, University "La Sapienza," Moro 5, 00185 Rome, Italy; e-mail: carlo.presutti@uniroma1.it; fax: 390649917827.

Article published online ahead of print. Article and publication date are at http://www.rnajournal.org/cgi/doi/10.1261/rna.251907. component of snoRNP, target specific sequences on prerRNA for nucleotide modification: box C/D snoRNAs cause 2'-O methylation (Cavaille et al. 1996; Kiss-Laszlo et al. 1996), while box H/ACA originate pseudouridylation (Ganot et al. 1997; Ni et al. 1997). In both these processes, the modification reactions are guided by a joining of complementary regions extended for 10-21 nucleotides (nt) between the rRNA and the snoRNA.

The genomic localization of sequence coding for snoRNAs is peculiar: in vertebrates, they are localized within introns of both host gene coding or noncoding for proteins (Weinstein and Steitz 1999).

In most cases, snoRNAs are released from excised debranched introns by exonucleolytic trimming (Tycowski et al. 1993), while a minor pathway involves endonucleolytic cleavage of flanking sequences and a direct processing of the host pre-mRNA (Fragapane et al. 1993; Laneve et al. 2003). In the yeast Saccharomyces cerevisiae, most of the snoRNAs are transcribed by independent transcription of 
mono- or polycistronic precursors, while a minority is contained within introns of gene coding for proteins that are usually involved in translation machinery.

The processing of intronic snoRNAs mostly relies on elements within the snoRNA region: exonucleolytic trimming and accumulation of intronic C/D box snoRNAs depends on boxes $\mathrm{C}$ and $\mathrm{D}$ and on short flanking sequences at the ends of the snoRNA, which join each other to bring together the $5^{\prime}$ and $3^{\prime}$ ends (Watkins et al. 1996). This terminal structure binds four core snoRNP proteins that are conserved from human to yeast: fibrillarin (Nop1p in yeast), Nop58p/Nop5p, Nop56p, and $15.5 \mathrm{kDa}$ (Snu13p) (Filipowicz and Pogacic 2002). To the terminal core motif, $15.5 \mathrm{kDa}$ binds, and interestingly is also part of the U4 snRNP, where it binds to a similar RNA fold called the $\mathrm{K}$ turn (Nottrott et al. 1999). Fibrillarin is an abundant nucleolar protein, generally believed to be the 2'-O-methyltransferase (Tyc and Steitz 1989; Galardi et al. 2002). Nop56p and Nop58p are related; both interact directly with snoRNA (Gautier et al. 1997; Cahill et al. 2002). The binding of $15.5 \mathrm{kDa}$ to the terminal motif is essential for the association of the remaining snoRNP proteins (Watkins et al. 2002). Considering the very rapid processing of snoRNA precursors (Moore et al. 1993), the assembly of these proteins on the snoRNA is likely to occur on the lariat or directly on the pre-mRNA (Giorgi et al. 2001).

At least in mammals, the biosynthesis of intronic C/D box snoRNAs has been correlated to the position of the snoRNA-coding sequence inside the intron, and optimal distances between the snoRNA-coding sequence and conserved intron elements like the $3^{\prime}$ end and the branch point (BP) have been defined (Hirose and Steitz 2001; Hirose et al. 2003). Recent studies demonstrate that human intronic box H/ACA snoRNA genes possess no preferential localization with respect to intronic splice sites and that they originate in a splicing-independent manner (Richard et al. 2006). Here we report that in yeast the expression of $C / D$ box snoRNA precursors, when the positions of the snoRNA were altered with respect to important splicing sequences, leads to a strong decrease in the production of snoRNA. Remarkably, the splicing effectiveness of host introns also is affected, suggesting the existence of interactions between the splicing machinery and proteins responsible for snoRNA biosynthesis and accumulation.

\section{RESULTS}

In yeast, only seven snoRNAs are encoded within introns, while in mammals almost all C/D box snoRNAs are encoded within introns. Figure 1 shows a schematic representation of snoRNA position in yeast introns and indicates the distances between snoRNAs, $5^{\prime}$ - and $3^{\prime}$-splice sites, and the BP. All six C/D box snoRNAs are located $>105 \mathrm{nt}$ upstream of the $3^{\prime}$-splice site, with a maximum of 227 , while the distances between the $5^{\prime}$-splice site and the
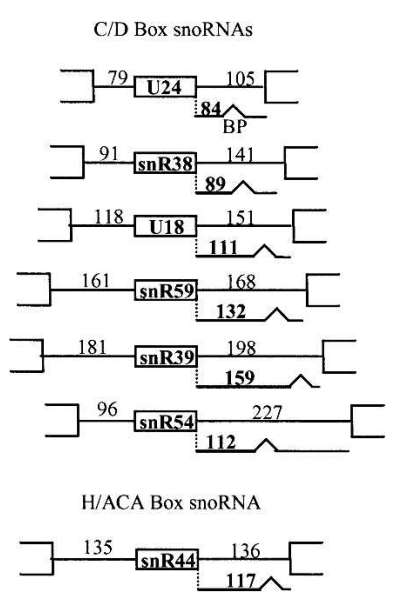

FIGURE 1. Schematic representation of yeast snoRNA positions within their host introns. Spacer lengths are indicated. Drawings are not to scale.

snoRNA 5' are between 79 nt and 181 nt. The BP distances from the relative snoRNA are from $84 \mathrm{nt}$ to $159 \mathrm{nt}$.

We analyzed U24 and U18 C/D box intron encoded snoRNAs that are located 84 and $111 \mathrm{nt}$ upstream of the $\mathrm{BP}$ and 79 and 118 downstream from the $5^{\prime}$-intron splice sites in their respective genes, $A s c I$ and $E F 1-\beta$. We chose to study these two snoRNAs because they originate through different pathways: while U24 completely depends on splicing for its biosynthesis, U18 can also be produced from a secondary pathway that includes EF1- $\beta$ pre-mRNA direct processing. To investigate the role of proper spacing between snoRNA-coding regions and intron splicing sequences, we analyzed the biosynthesis of the snoRNAs and the processing of the host introns in a series of constructs where this spacing was altered.

\section{Alteration of $\mathrm{U} 24$ position within host intron strongly affects both splicing and snoRNA synthesis}

Figure 2A shows the constructs for U24 snoRNA. Wildtype U24 comprises the whole coding region of the AscI gene from +1 to +1233 with respect to the ATG; a tag sequence was inserted within the U24-coding region in a position where it does not affect snoRNA function and biosynthesis (Villa et al. 1998). Distances between the snoRNA and splice sites are indicated. Production of U24 snoRNA and AscI pre- and mRNA were monitored by Northern blot (Fig. 2B,C).

Deletions of either the downstream spacer (BP-44) or the upstream spacer $\left(5^{\prime}-39\right)$, cause a great decrease in snoRNA synthesis (Fig. 2B,D, first histogram). When the distance between the snoRNA and BP is reduced to $44 \mathrm{nt}$, the accumulation of U24 is totally abolished (lanes BP-44), and it is barely detectable when the deletion encompasses $40 \mathrm{nt}$ in the upstream spacer, reducing it to $39 \mathrm{nt}$ (Fig. 2B,D, lanes 5'-39). Remarkably, the level of U24 was also diminished when the downstream spacer was extended 
A

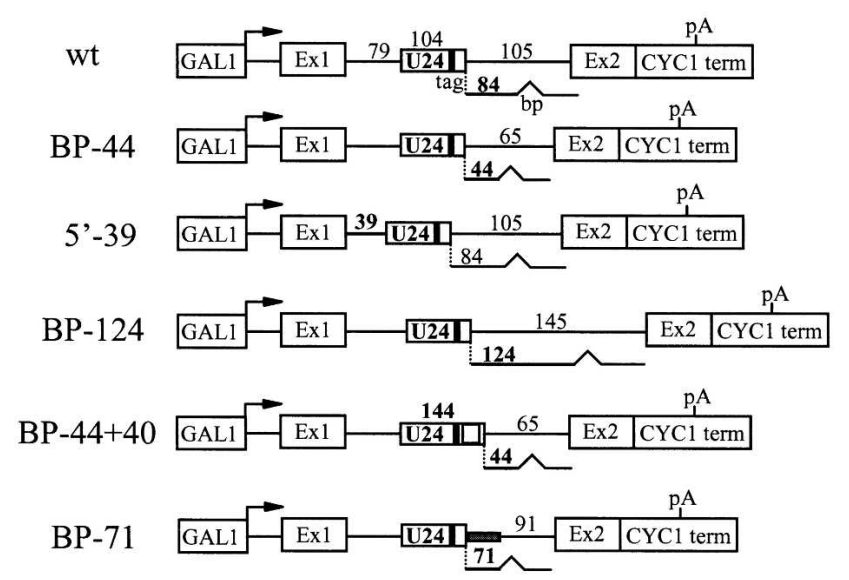

B

$\begin{array}{lllllllllllll}\text { Gal-hrs: } & 0 & 1.5 & 3 & 0 & 1.5 & 3 & 0 & 1.5 & 3 & 0 & 1.5 & 3\end{array}$

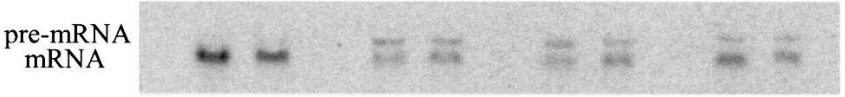

$\mathrm{U} 24$

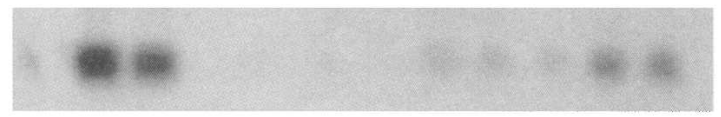

$\alpha$-snr190
C

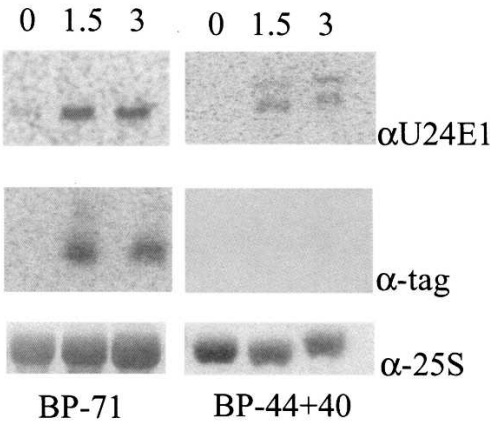

D
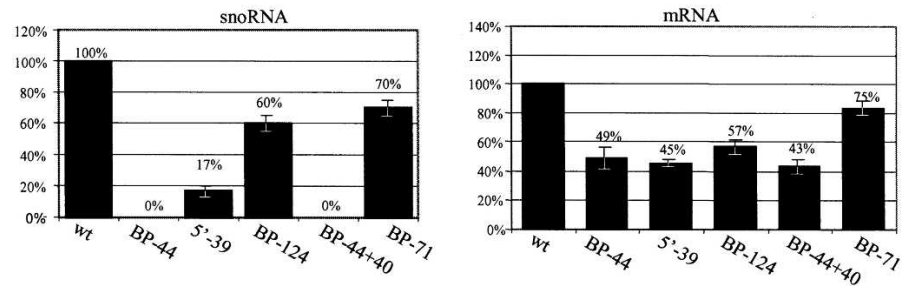

FIGURE 2. Analysis of U24 processing. (A) The constructs shown were used to transform wild-type strain YAF3 (see Table 2); the dark box within the U24 snoRNA-coding region represents the tag sequence; BP indicates the branch point and pA the polyadenylation site within the CYC1 terminator. Deletion and insertion mutations made in the upstream and downstream spacers are shown. The white box within the U24BP-44+40 construct represents $40 \mathrm{bp}$ inserted between the $\mathrm{D}^{\prime}$ and $\mathrm{C}^{\prime}$ boxes; the gray box schematized within the BP-71 mutant host intron represents a 27-ntlong random sequence added to the BP-44 mutant. $(B, C)$ Total RNA was extracted after induction in galactose medium at different times reported above each lane. Total RNA was hybridized with the oligonucleotides reported in each panel. Upper panels show the pre-mRNA accumulation, lanes $B P-44,5^{\prime}-39, B P-124(B)$ and lanes $B P-71, B P 44+40(C)$ and the mRNA levels. Lower panel shows U24 production. These filters were hybridized with oligonucleotides $\alpha$-snR190 (B) and $\alpha-25 S(C)$ as a control. $(D)$ The left histogram summarizes the accumulation of U24 snoRNA and the right histogram shows the levels of the host gene mRNA. The quantifications reported in these histograms were referred to 3-h galactose addition points.

(from $84 \mathrm{nt}$ to $124 \mathrm{nt}$ ) (Fig. 2B,D, lanes BP-124). This latest result suggests that a proper length of the $3^{\prime}$ spacer is required for efficient snoRNA biosynthesis. Recently the importance of IBP160 (splicing intron binding protein) was elucidated in mammals (Hirose et al. 2006). This RNA helicase interacts with U2 snRNP, probably via SF3b components. This interaction is strongly affected by the correct position of the snoRNA-coding regions inside the host intron. The proper spacing is probably intron specific and could be slightly variable for different snoRNAs.

The splicing of the exogenous host introns was affected in all these mutants: the mRNA amount was reduced to $\sim 50 \%$. Accumulation of pre-mRNAs originating from these constructs is also evident (Fig. 2B,D, second histogram). 
In order to demonstrate that these effects are not due to the shortening or lengthening of the intron itself, $40 \mathrm{nt}$ were inserted within the snoRNA-coding sequence. This returns the intron's length to its original size, leaving the distance between the snoRNA $3^{\prime}$ and BP at 44 nt. As shown in Figure 2C, lanes BP-44+40, this insertion is not able to restore efficient splicing, indicating that these effects are not simply due to the variation of the intron length. On the contrary, lengthening the downstream spacer to $71 \mathrm{nt}$ by adding a 27-nt-long unrelated sequence to the BP-44 mutant (BP-71) (Fig. 2A,C) largely re-establishes U24 production and AscI pre-mRNA splicing, indicating that the effects observed in U24 position mutants are not due to the deletion of specific sequences but rather to the alteration of an optimal distance with respect to the branch point.

\section{Production of U18 snoRNA located at suboptimal position can be restored by secondary cleavage pathway}

U18 yeast snoRNA is synthesized by two different mechanisms: a major pathway proceeds through exonucleolytic degradation of the excised EF1- $\beta$ intron, while a minor pathway implicates endocleavage(s) of EF1- $\beta$ pre-mRNA and subsequent trimming of intermediate molecules (Villa et al. 2000; Giorgi et al. 2001).

Figure 3 shows the effects of altering the distance between the U18 snoRNA-coding region and the BP of its host intron. Wild-type U18 comprises a portion of the EF1- $\beta$ gene-coding region from -24 to +524 with respect to the ATG. This region encompasses the first exon, the following intron, and part of the second exon. Accumulation of U18 snoRNA and its precursors was analyzed by Northern blot, after transformation of a yeast wild-type strain, W303-1B.

The exogenous U18 copy is identifiable by the presence of a tag sequence previously shown to be unimportant for snoRNP assembly and function. As previously observed, the U18 signal is visualized even before galactose addition to the medium (Fig. 3B, lanes Gal 0), suggesting that some transcription also occurs in nonrepressing conditions (Villa et al. 1998).

The deletion of $40 \mathrm{nt}$ in the downstream spacer causes a decrease in U18 RNA accumulation; however, the effect is small compared to the one observed for U24. In the construct where the distance between the $3^{\prime}$ of U18 and BP was further reduced to $45 \mathrm{nt}$, U18 snoRNA presence is still evident. In all these mutants, splicing of the host intron is affected: shortening of the downstream spacer causes EF1- $\beta$ pre-mRNA accumulation and the appearance of I-2 and I-3 processing intermediates (see below). In these experiments it is difficult to appreciate the exact amount of GAL-driven EF1- $\beta$ mRNA because its signal either overlaps or is very close to the I-2 intermediate in Northern experiments. Quantitative PCR analysis indicates that mRNA accumulation in these mutants varies from $50 \%$ to $70 \%$ with respect to wild type (data not shown).
As mentioned above, there are two different pathways leading to U18 biosynthesis. To analyze the effect of spacer shortening in both pathways, we alternatively blocked splicing or cleavage processing and tested alteration of spacer length in these conditions.

Figure 3 also shows the experiments performed on an EF1- $\beta$ minigene construct in which the U18 host intron splicing was abolished by mutation of $5^{\prime}$ cis-splicing sequences (Villa et al. 2000). In these series of mutants all the U18 comes from the endonucleolytic cleavage-dependent pathway. As expected in these constructs, we observe a pre-mRNA increase and the appearance of processing intermediates deriving from cleavages on pre-mRNA. The U18 amount is only slightly decreased (Fig. 3C, lanes 5' C5, $\left.5^{\prime} \mathrm{C} 5 / \mathrm{BP}-71\right)$, indicating that the minor endonucleolyticdependent pathway can compensate the absence of an efficient ongoing splicing at least in the production of U18 snoRNA (Villa et al. 1998). Indeed, the appearance of cleavage intermediates (I-2 and I-3) supports this conclusion: when the pre-mRNA accumulates due to defective splicing, a large part of it can be processed through the alternative endonucleolytic pathway, leading to a normal accumulation of U18 snoRNA. Nevertheless, a light decrease of U18 production is observed in $5^{\prime} \mathrm{C} 5 / \mathrm{BP} 71$, indicating that the position of the snoRNA-coding region affects the cleavage-processing pathway.

\section{Mutations in external stem completely impair efficiency of pre-mRNA splicing when U18 snoRNA is not optimally located within the host intron}

The importance of the U18-coding region position within its host intron is evidenced when the complementary hairpin sequence of the Rntlp endonuclease target region, which is necessary to direct EF1- $\beta$ pre-mRNA processing, is mutated and its external stem structure is disrupted (Fig. 4C). Intriguingly, Northern blot experiments show that not only is U18 synthesis completely dependent on the presence of an intact stem structure (Fig. 4B, lanes $\Delta$-stem, $\Delta$-stem/BP-43), but also that host intron splicing is strongly affected, too (Fig. $4 \mathrm{~B}$, lanes $\Delta$-stem/BP-43). We observe a strong increase in EF1- $\beta$ pre-mRNA accumulation, which is not related to the appearance of cleavage intermediates or to mature mRNA. In this mutant, although pre-mRNA accumulates it cannot be processed in any productive way, suggesting that not only biosynthesis of U18 snoRNA but also the splicing of the host intron containing the snoRNA-coding region are strongly dependent on correct snoRNP assembly (S. Vincenti, unpubl.).

\section{The absence of snoRNA-binding proteins cannot restore splicing efficiency of the host intron}

To determine whether the effects observed in our experiments on splicing efficiency and snoRNA release depend on 
A

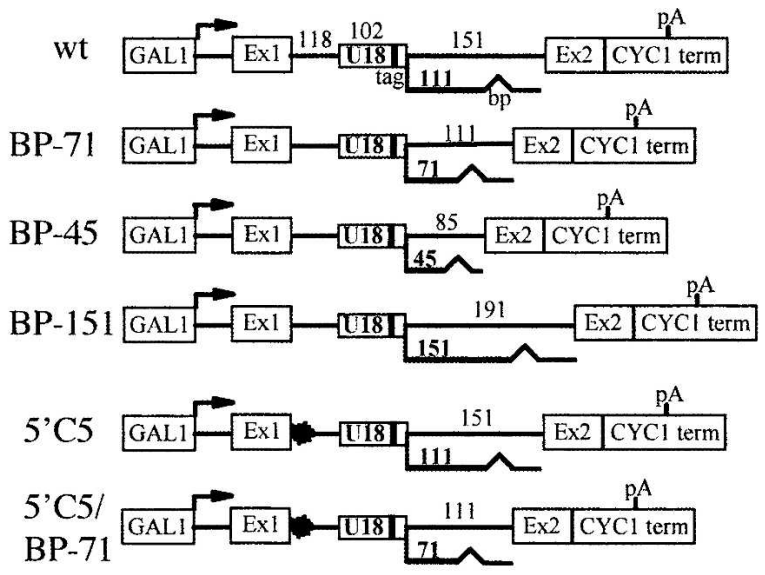

B

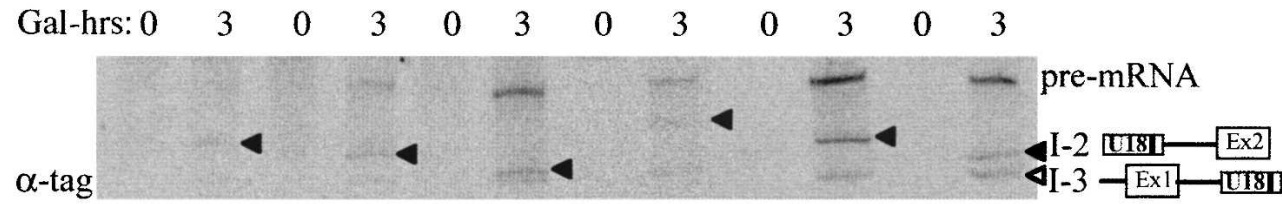

$\alpha-\operatorname{tag}$

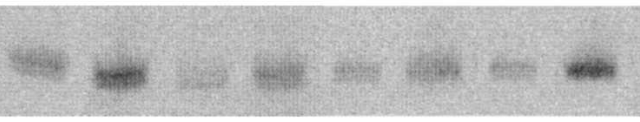

U18

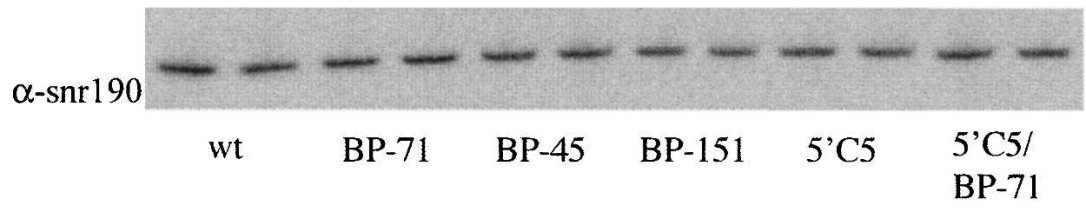

C

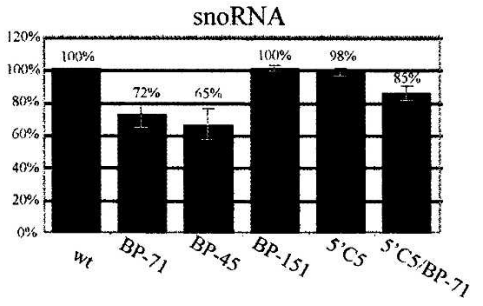

FIGURE 3. Analysis of U18 processing. (A) Drawing of the plasmids used to transform yeast wild-type strain W303-1B. The dark box within the U18 coding region represents the tag sequence; $\mathrm{pA}$, the polyadenylation site; and $\mathrm{BP}$, the branch point. The dark spots drawn at the end of the first exon represent the $5^{\prime}$-splice site mutated $\left(5^{\prime} \mathrm{C} 5\right.$ and $\left.5^{\prime} \mathrm{C} 5 / \mathrm{BP}-71\right)$. The deletions and insertions made between the $3^{\prime}$ end of the U18 snoRNA and the branch site are shown. (B) RNA was extracted at different times after galactose induction (indicated above each lane) from the strains transformed with the plasmids: pGALU18WT, pGALU18bp-71, pGALU18bp-45, pGALU18bp-151, pGAL1U18-5'-C5, and pGALU18-5'-C5bp71. (Upper panel) pre-mRNA and intermediates I-2 and I-3, which are depicted on the side and indicated by black and white arrowheads, respectively. (Bottom panel) U18 snoRNA; U18 signal was visualized even before galactose addition to the medium (lane Gal 0), suggesting that some transcription also occurs before induction (Villa et al. 1998). (Lowest panel) A hybridization control using an $\alpha$-snr190-specific probe. (C) The histogram displays the accumulation of U18 snoRNA. The quantifications reported are as indicated in Figure 2.

a competition between snoRNPs and splicing factors due to their binding site mutual closeness, we designed constructs mutated in the U24 and U18 C-box (Fig. 5A). Mutations in the C-box are known to affect both snoRNA biosynthesis and stability (Lafontaine and Tollervey 1999). In the U24bC mutant, the assembly of snoRNPs is impaired, and consequently U24 snoRNA accumulation was totally inhibited (data not shown). To define the possible relationships between the splicing machinery and snoRNP proteins, we generated a U24-BP44/bC mutant in which the distance between the snoRNA and BP was reduced to $44 \mathrm{nt}$ and the C-box was mutated. Remarkably, the 
A

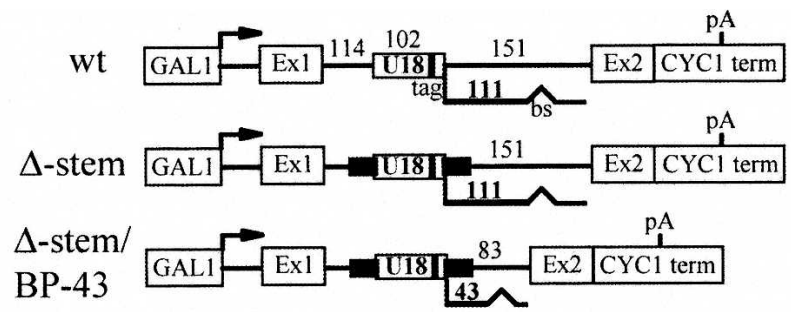

B

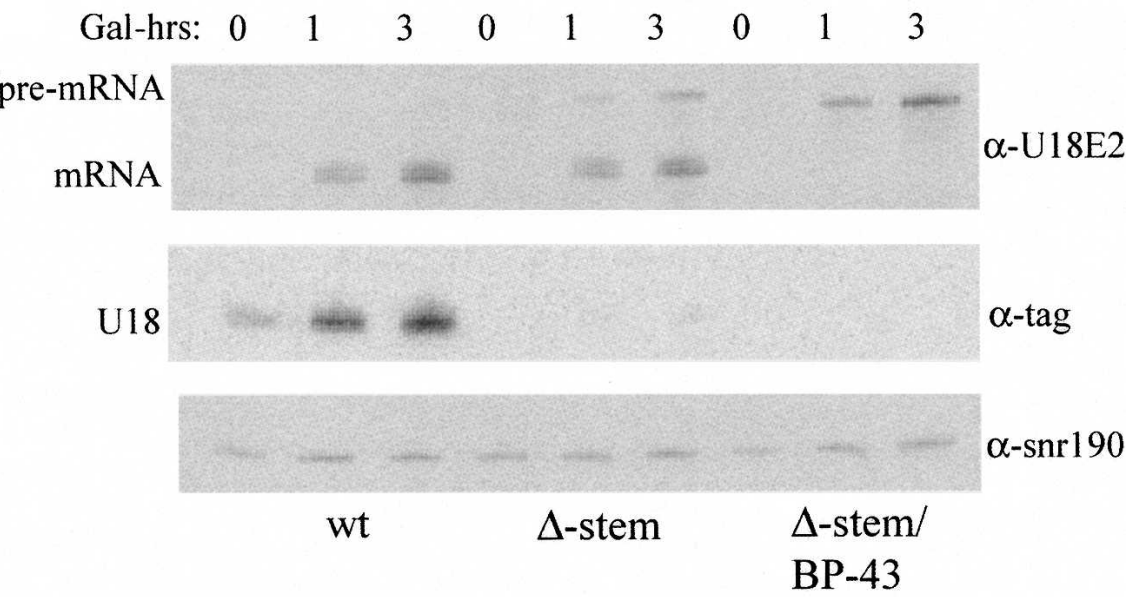

C
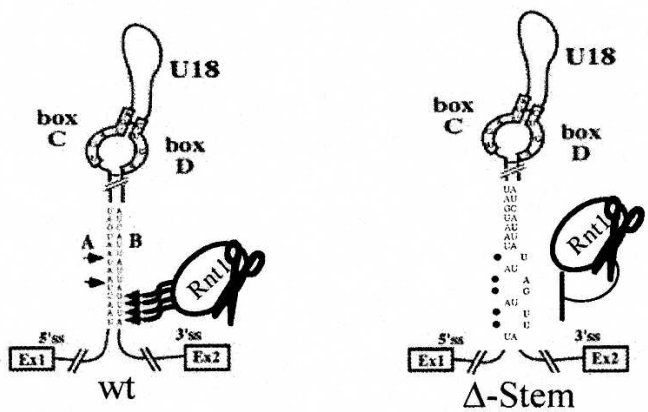

D
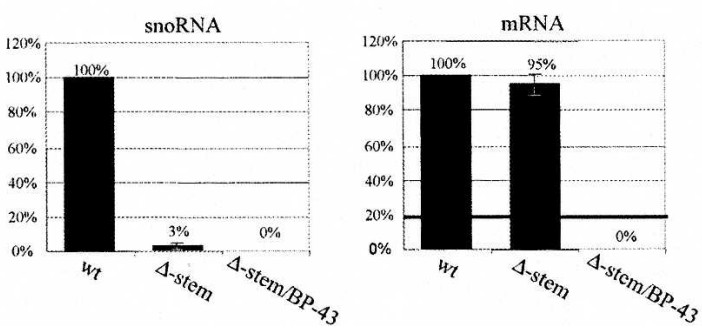

FIGURE 4. Processing of the different U18 constructs. (A) Schematic representation of the plasmids used to transform the yeast wild-type strain W303-1B. The dark box at the $5^{\prime}$ and $3^{\prime}$ ends of the U18 coding region in the constructs $\Delta$-Stem and $\Delta$-Stem-BP-43 indicates mutated external stem structures. $(B)$ Northern blot analysis: total RNA $(5 \mu \mathrm{g})$ was hybridized with the probes indicated on the side. (Upper panel) pre-mRNA and mRNA accumulation; (bottom panel) U18 snoRNA. The filter was hybridized with oligonucleotide $\alpha$-snR190 as a control. $(C)$ Representation of U18 host intron secondary structure of wild-type and $\Delta$-stem constructs. The cleavage sites of Rntlp are indicated by arrows. Introduced point mutations inhibit Rnt 1 cleavages. $(D$, left $)$ The histogram shows U18 snoRNA accumulation; (right) the levels of the host gene mRNA. The quantifications reported are as indicated in Figure 2.
U24-BP44/bC mutant accumulates unspliced pre-mRNA at comparable levels with respect to U24-BP-44, indicating that the absence of snoRNAbinding proteins cannot restore the splicing efficiency of the host intron (Fig. 5B). Considering these results, the analysis was extended to the U18 snoRNA. The U18 $\Delta$-stem/BP-43 construct, whose splicing efficiency is strongly affected (Fig. 4B), was mutated at the C-box to produce the U18 $\Delta$ stemBP43/bC mutant (Fig. 5A). Again, these point mutations completely impair snoRNP assembly. Northern blot analysis (Fig. 5C) shows the same premRNA accumulation observed in the U18 $\Delta$-stem/BP-43 mutant (Fig. 4B). The failure in restoring host intron splicing, observed in the U24-BP44/bC and $\mathrm{U} 18 \Delta$ stem-BP43/bC constructs, led us to exclude an antagonism between snoRNPs and splicing machinery when the distance between the snoRNAs and branch point is shortened.

\section{Nop1p and Nop58p are recruited on actively transcribed C/D-box snoRNA genes}

Previous indications in both yeast and mammalian cells suggested that assembly of snoRNA proteins occurs cotranscriptionally. The yeast H/ACA proteins Naflp, Cbf5p, and Nhp2p bind to the nascent RNA transcript, controlling the $3^{\prime}$-end formation of snoRNAs and the release of a functional particle (Ballarino et al. 2005). In mammalian cells, recognition of intronic box H/ACA snoRNAs is cotranscriptional and splicing independent (Richard et al. 2006). On the contrary, this and previous works indicate that $\mathrm{C} / \mathrm{D}$-box snoRNA biogenesis is strictly related to efficient splicing and that the protein factors of the two machineries can cross-talk to ensure proper functioning of both processes.

Most likely some splicing factors recruit and deposit Snu13p on intronic snoRNA, which has an optimal location with respect to splicing consensus sequences. This assembly occurs in mammals at the $\mathrm{C} 1$ complex stage. While assembly of some splicing factors was 


\section{A}
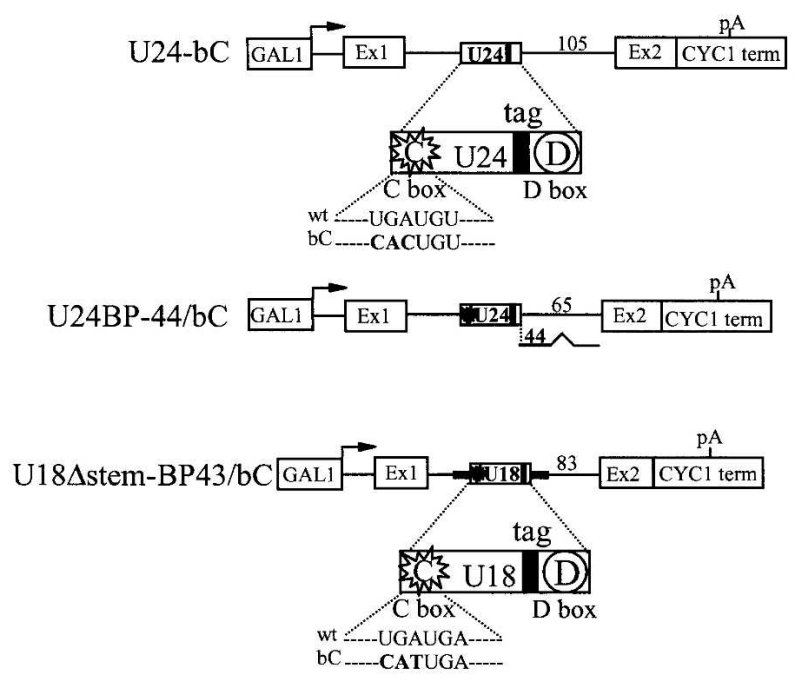

B

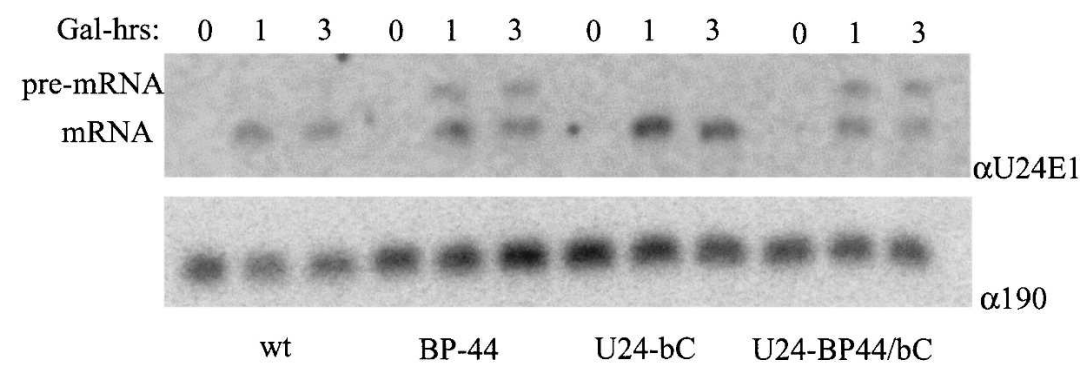

C

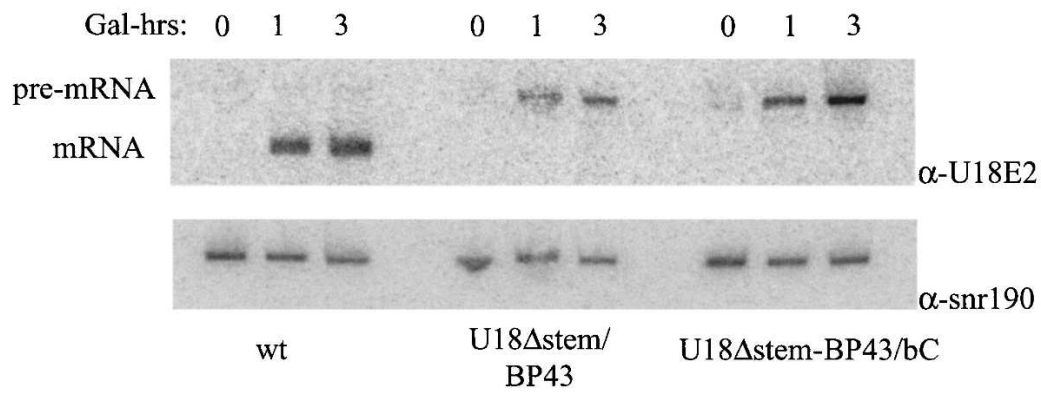

FIGURE 5. (A) The constructs shown are used to transform wild-type strain YAF3 (see Table 2). The C-box sequence was mutated as shown in bold (U24-bC); the downstream spacer of this construct was shortened to give U24-BP44/bC, as shown. The C-box mutation in the U18Dstem$\mathrm{BP} 43 / \mathrm{bC}$ construct is shown in bold; this construct was used to transform the W303-1B yeast strain (see Table 2). (B) Northern blot experiment: total RNA $(5 \mu \mathrm{g})$ was extracted at different times after galactose induction, and than hybridized with $\alpha$-U24E1 (upper panel) and $\alpha$-snr190 (lower panel) probes; pre-mRNA and mRNA products are indicated on the left. (C) Northern blot analysis: total RNA $(5 \mu \mathrm{g})$ was hybridized with probes indicated on the side; (upper panel) pre-mRNA and mRNA levels; (lower panel) hybridization control (snr190). a strain carrying a C-terminal TAPtagged version of Nop58p and Nop1p proteins (see Table 2 below). The immunoprecipitated DNA was analyzed by PCR amplification for the presence of snoRNA U24 and U18 coding regions and for DNA regions corresponding to promoters of the host genes. Each gene was analyzed with two different couples of primers (Fig. 6, schematic representation above histograms): the first couple (Fig. 6, primers a,c) recognizes promoter sequences, while the second one (Fig. 6, probes $b, d, e)$ is specific for the transcribed regions. Histograms A and B in Figure 6 indicate the presence of high levels of Nop58p on the coding regions of box C/D snoRNA genes (black boxes), while the amount of protein recruited on promoter regions remains close to the background (gray boxes).

To better define the importance of snoRNA structure in recruitment of snoRNP proteins, we carried out ChIP experiments on plasmid containing wild-type $\mathrm{U} 24$ and bC mutant constructs. The ChIP experiment in Figure 6C, wt-Gal, shows that Nop58 recruitment occurs efficiently when wild-type U24 production is driven by the Gal promoter. In the absence of a proper K-turn motif (U24bC mutant), Nop58p is not associated with the U24 snoRNAcoding region. This result marks the importance of the correct structuring of this region for proper assembly of snoRNP proteins and the consequent production of a mature snoRNP particle. Furthermore, under repressive transcriptional conditions (Fig. 6C, wt-Glu and patterned box wt-Glu in histogram), there is no association of Nop58p with chromatin, indicating that Nop58p recruitment needs ongoing transcription. ChIP experiments carried out in strains expressing Nop1- and Nop56-tagged proteins show the same results (data not shown). demonstrated to be cotranscriptional (Kotovic et al. 2003), little is known about the assembly of the box C/D snoRNP.

To test the possibility that C/D-box snoRNP assembly also is dependent on RNA Pol II transcription, Chromatin immunoprecipitation (ChIP) assays were performed with

\section{DISCUSSION}

In yeast, a few snoRNAs are encoded within introns of host genes, while the majority are independently transcribed in mono- or polycystronic genomic organization. 
A
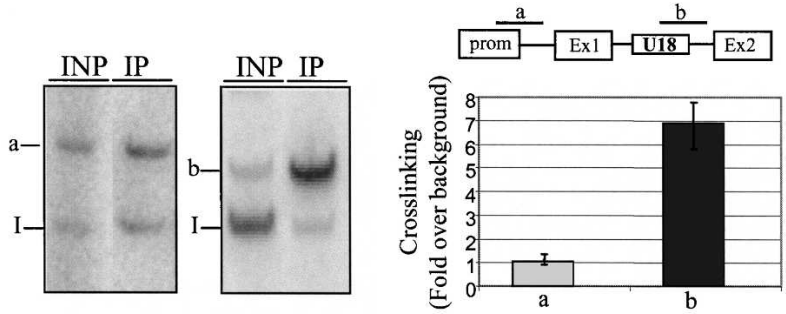

B
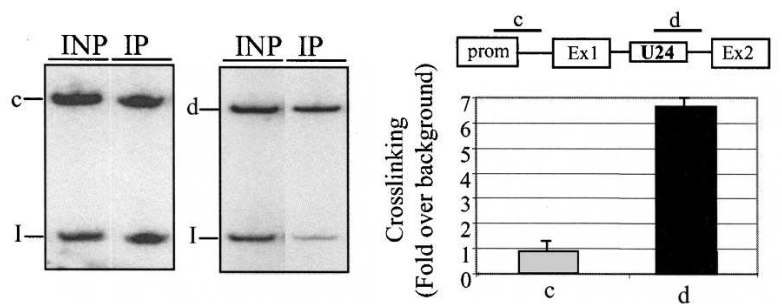

C
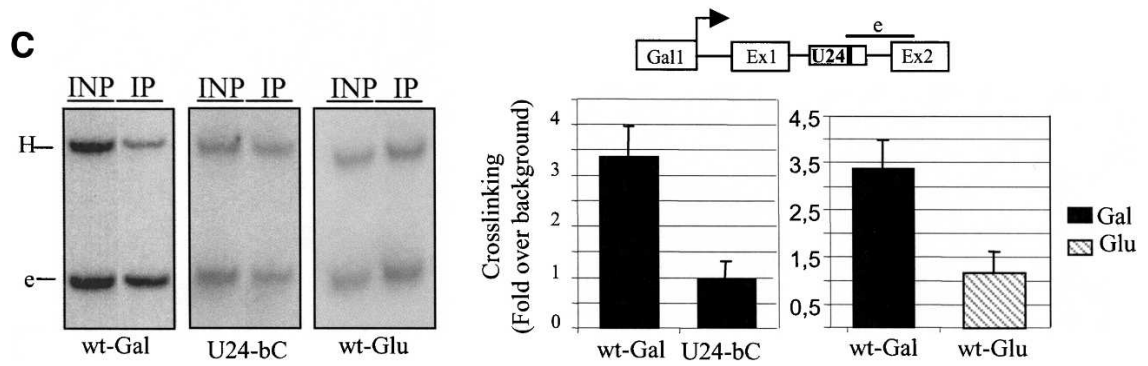

FIGURE 6. Experiments of chromatin immunoprecipitation. $(A, B)$ PCR amplifications before (INP) and after (IP) immunoprecipitation performed on Nop-58-tagged protein. Underscored $a, b, c$, and $d$ above the schematic diagrams of the EF1- $\beta$ and Ascl genes indicate the products obtained by PCR amplification; a nontranscribed intergenic region of Chromosome $\mathrm{V}$ used as an internal control is indicated as I on the left of $A$ and $B$. Histograms displaying the degree of Nop58p cross-linking on the promoter (gray boxes) and snoRNA (black boxes) coding regions. The data are presented as the average of signals of five different PCRs. Values on the $Y$ axis are expressed as fold over background. (C) ChIP experiments were performed on U24wt (wt-Gal, first histogram) and U24-bC mutant (U24-bC, first histogram). ChIP experiments performed under repressive transcriptional conditions (adding 4\% glucose to the medium; wt-Glu) show no Nop58 immunoprecipitation (patterned box in the second histogram). PCR amplifications were performed before (INP) and after (IP) Nop58p immunoprecipitation. The underscored $e$ indicates the amplification products of the snoRNA regions specified above the Ascl schematic diagram. $\mathrm{H}$ on the left of the panels indicates the ARSH4 amplified plasmid region used as an internal control.

This is different compared to the mammal case, where almost all snoRNAs are contained in introns. Despite this peculiar genome location, the functional relationship between production of intron-encoded RNAs and splicing of host pre-mRNAs is poorly understood. In this study, we show that a correct position of yeast box C/D snoRNAs within their host introns is crucial for their biosynthesis and important for efficient splicing of the precursors. Expression of exogenous constructs with altered distances of snoRNA coding regions with respect to splicing important sequences leads to the absent or very low production of snoRNA as well as to less efficient splicing of the host introns. This finding is remarkably different from what was described in mammalian cells, where the splicing process is unaffected by the position of snoRNA sequences.
Our experiments suggest that the most important element responsible for correct U24 snoRNA biosynthesis and efficient splicing of the host intron is the distance between the $3^{\prime}$ end of the snoRNA-coding region and the branch point: if it is shortened to $44 \mathrm{nt}$, snoRNA synthesis is abolished. This finding is in accord with data in mammals, where the shortening of the downstream spacer to $41 \mathrm{nt}$ causes a drastic reduction in the U76 snoRNA amount. The alteration of distances between the snoRNA-coding region and splicing sequences leads to a decrease of splicing efficiency of $\sim 50 \%$, and to a complete disappearance of the snoRNA: it seems that snoRNP assembly is more sensitive than spliceosome activity to the correct position of snoRNA-coding sequences inside the intron.

A possible explanation for these results is that the splicing machinery and factors responsible for snoRNA biosynthesis can interfere with each other. However, increasing the length of the downstream spacer also negatively affects both snoRNA synthesis and splicing of the host intron, although to a minor extent. This finding indicates that not only can the components of the two machineries interfere with each other, but it also suggests the existence of a suited network of interactions.

It is important to note that less efficient splicing is not purely due to intron size. Indeed, a 40-nt-long insertion of mutant BP-44 into snoRNAcoding sequences that sets back the intron's total length to its normal $288 \mathrm{nt}$ without changing the mutant condition of the 44-nt-long distance between the snoRNA and the BP is not able to restore splicing. In addition, the splicing impairment is not due to deletion of important sequences: in mutant BP-44 when the distance between the $3^{\prime}$ end of the snoRNAcoding sequence and the branch point is lengthened to $71 \mathrm{nt}$ by adding 27 random nucleotides (BP-71 mutant), the splicing effectiveness as well as snoRNA biosynthesis are restored, indicating that distance is crucial for the proper occurrence of the two processes, yet not the sequence.

To better characterize the network of interactions between macromolecular complexes responsible for splicing and snoRNP biosynthesis, we decided to analyze another snoRNA, U18, which is produced in a different way. While U24 originates almost exclusively from exonucleolytic 
processing of the released lariat, U18 has a more complicated biosynthesis, namely, there exists an alternative production pathway based on direct processing of the pre-mRNA of the host gene. This alternative pathway goes through endonucleolytic cleavage(s) of the pre-RNA and subsequent processing of cleavage intermediates. It is responsible for $\sim 30 \%$ of the U18 snoRNA amount. This minor pathway is dependent on the presence of a secondary stem structure: an inverted repeat in the EF1- $\beta$ intron just outside the U18coding sequences (external stem). This structure is present in many introns from yeast to mammals, where it plays a role in enhancing the efficient splicing of the contained introns (Goguel and Rosbash 1993; Howe and Ares 1997). At the same time, it is the molecular target of protein factor(s) responsible for the endocleavage of the pre-mRNA leading to U18 biosynthesis (Giorgi et al. 2001).

The alteration of the U18 coding region position inside the host intron affects the splicing efficiency according to what was observed for the U24 position mutants. However, it has little effect on U18 snoRNA accumulation. This is due to the existence of an alternative pathway, which can compensate the defective splicing-dependent pathway. This result is confirmed by complete inhibition of splicing in the C5 mutants, in which U18 production is unaffected.

Inhibition of the secondary processing pathway by disruption of an inverted repeat present in the EF1- $\beta$ intron causes the disappearance of U18 snoRNA and slightly affects splicing (Villa et al. 2000; Hirose et al. 2003).

Coupling disruption of the stem with alteration of the U18 coding region position within the EF1- $\beta$ intron $(\Delta$-stem/BP-43) causes both pathways operating on this pre-mRNA to be completely inactivated. The precursor cannot be processed or spliced at all; thus, the absence of a functional external stem reveals the importance of the correct position of the U18 coding region for ongoing splicing of the host intron.

Mutations of snoRNA sequences important for snoRNP assembly give interesting results. Disruption of the C-box in U24 (U24-bC) completely destabilizes it; consequently, we could not observe any accumulation of snoRNA. However, failure of snoRNP assembly permits a remarkable observation: the splicing efficiency of the U24 shortened construct (BP-44) cannot be rescued in the absence of snoRNPs (U24-BP44/bC). This finding strongly suggests that defective splicing is not due to a simple steric hindrance between the two macromolecular complexes but probably is due to the loss of an ordered network of interactions.

The same results were obtained by inactivation of the U18 C-box in the $\Delta$-stem/BP-43 construct (U18 $\Delta$ stem$\mathrm{BP} 43 / \mathrm{bC}$ ), where the loss of snoRNP assembly could not rescue the splicing of the host pre-mRNA.

Taken together, these data reveal that inefficient splicing and defective snoRNA accumulation in shortened constructs are not caused by steric competition of the two macromolecular complexes. Our results also suggest that components of the splicing machinery that make contact with splicing consensus sites can play a role in C/D-box snoRNA synthesis, too. This is in good accordance with what was demonstrated by Hirose and Steitz (2001): in their in vitro system, $15.5 \mathrm{kDa}$ and fibrillarin associate with snoRNA sequences in a splicing-dependent manner; the binding of these proteins occurs when the splicing complex reaches the $\mathrm{C} 1$ stage, and it is strongly perturbed if the snoRNA is not properly located within the host intron (Hirose et al. 2003). In our in vivo system, snoRNP recruitment occurs cotranscriptionally on snoRNA-coding regions when assembly of spliceosome factors takes place, indicating an interaction between the two macromolecular machineries. However, other factors can affect this process. Some snoRNAs assemble snoRNPs in a splicing-independent manner. This happens for those snoRNAs that are not optimally located within host introns. These snoRNAs usually possess stable external stems. These stems have already been suggested to be involved in enhancing splicing as well as snoRNP assembly and biosynthesis (Villa et al. 2000; Giorgi et al. 2001). Both Hirose's work and our work suggest that they participate in snoRNP recruitment and that this action can compensate the suboptimal location of snoRNA-coding sequences within host introns. The relative importance of snoRNP assembly in helping the splicing process probably depends on the intron itself: introns with suboptimal splicing consensus sequences are presumably more dependent on correct snoRNP assembly. Many sequences/structures can also contribute to this process: external stems (both in yeast and mammals), splicing enhancers, and hnRNPs. The coordinated action of all these sequences and factors determines the efficiency of the splicing process for every different intron.

Pre-mRNA introns that are removed by splicing are rapidly degraded. Therefore, active recruitment of snoRNP proteins during pre-mRNA synthesis and/or splicing is probably crucial for efficient intronic snoRNP production. Demonstration in which intronic snoRNP assembly is actively promoted by machines that are involved in premRNA biogenesis and that snoRNPs are cotranscriptionally present on snoRNA-coding regions indicates that "the functional complexity of the 'mRNA factory' exceeds our previous expectations" (Ares and Proudfoot 2006; Richard and Kiss 2006). The next step of this challenging work will be the characterization of protein-protein interactions that participate in splicing-dependent C/D-box snoRNP assembly.

\section{MATERIALS AND METHODS}

\section{Oligonucleotides}

The oligonucleotides used for different cloning steps and RNA analysis are reported in Table 1. 
TABLE 1. Oligonucleotides used for different cloning steps, RNA and ChIP analysis ( $\left.5^{\prime}-3^{\prime}\right)$

\begin{tabular}{|c|c|}
\hline U24TAG-f & GCAGTCCGCAGTTCCGAATGAGACATACCAATTATC \\
\hline U24TAG-b & CTGGATGCCGGTTCCATCTGAAGTAGCAAATATG \\
\hline U24bpSHORT-f & TGGAAACTTTTTTTTTAAATTAAT \\
\hline U24bpSHORT-b & AACCATTCATCAGAGATCTT \\
\hline U245'SHORT-f & TGCCATTCAAATGATGTAAT \\
\hline U245'SHORT-b & TATTCTATCATGGAAAGAAAATAT \\
\hline U24bpLONG-f & GAGAGATTTCTCTTTTACCTCTTTACTCGTTATGTCAAAATG \\
\hline U24bpLONG-b & GAGCAATTGGGACCGTGCAAAGAAGAGCAGAGTAATGCTA \\
\hline U24Cmut-f & CACTGTAATAACATATTTGCTA \\
\hline U24Cmut-b & TTTGAATGGCATACACAAATCC \\
\hline U24sno-long-f & GAGAGATTTCTCTTTTACCTTCCGAATGAGA \\
\hline U24sno-long-b & GAGCAATTGGGACCGTGCAAACTGCGGACTGCCTG \\
\hline SHORT-F & TGGAAACTTTTTTTTAATTAAT \\
\hline U24BP-SHORT+40B & GAGCAATTGGGACCGTGCAAAACCATTCATCAGAGATCTT \\
\hline$\alpha-U 24 \mathrm{E} 1$ & TGGTTGACCACCAGAAGTAG \\
\hline$\alpha$-tag & TGCGGACTGCCTGGATGCCG \\
\hline$\alpha$-snr190 & GGCTCAGATCTGCATGTGTT \\
\hline$\alpha-25 S$ & CTCCGCTTATTGATATGC \\
\hline Ex2U24orf-b & TGAAGTCAGCTTCAATTTGG \\
\hline U18bpSHORT-f & AGTCTAAAGATTGCATTACA \\
\hline U18bpSHORT-b(wt) & CAGATAACTAATAATGATAC \\
\hline U18bpSHORT-b(RS) & CAGATTTGATTATTACTAAC \\
\hline U18bpSHORT-BIS-f & AAGTTCTCATTACTAACAAG \\
\hline U18 $\Delta$ STEM-f & AGAGTTAGTAATGAGAACTT \\
\hline U18 $\Delta$ STEM-b & GCTCTGTGCTATCGTCAGAT \\
\hline antiU18DSTEM-f & AAGTTCTCATTACTAACTCT \\
\hline U18 $18 \mathrm{BIS}$ & GTTCTCATTACTAACAAGCA \\
\hline U18bpLONG-f & GAGAGATTTCTCTTTTACCTTTGCATTACAAGAAAAAAGT \\
\hline U18bpLONG-b & GAGCAATTGGGACCGTGCAATCTTTAGACTCTGTCTTTCT \\
\hline BamHI/U18C5-f & CGCGGATCCTCCAACCGAATATA \\
\hline Xhol/U18C5-b & CCGCTCGAGGTTGAACCATCTGAA \\
\hline U18bC/RS-b & TTCACATAAGCGAAAAAAAGTATA \\
\hline U18bC-f & CATTGAATTTATTCTTTGGTC \\
\hline$a(p U 18-f)$ & AACCTGCAGGTGAAGAAGCGCTTT \\
\hline a (pU18-b) & CGGTTGGACTCTTCAGTGCTGAAA \\
\hline b (ChIPU18-a) & CCTATGGTTACATGTAAAGGGAAG \\
\hline b (ChIPU18-b) & GATACTCTGCTCTGTGCTATCGTC \\
\hline$c(p U 24-f)$ & TGCTTCTCCAGCGAAAGTCTCAGA \\
\hline$c(p \cup 24-b)$ & TAGCCAAAGATGTGACCCAACCGT \\
\hline d (U24ChIP-f) & CACCATCATTTCTGCCGGTAACGA \\
\hline$d(U 24 C h I P-b)$ & GTTGTGACCGATGAAGTCAGCTCC \\
\hline e (Tag 5'-3') & CGGCATCCAGGCAGTCCGCA \\
\hline e (e2U24ORF) & TGAAGTCAGCTTCAATTTGG \\
\hline Intergenic-a & GGCTGTCAGAATATGGGGCCGTAGTA \\
\hline Intergenic-b & CACCCCGAAGCTGCTTTCACAATAC \\
\hline Ex2U24orf-b & TGAAGTCAGCTTCAATTTGG \\
\hline ARSH4-2r & TTTCTTAGGACGGATCGCTTGCCT \\
\hline ARSH4-f: & GTCTGTGTAGAAGACCACACACGA \\
\hline
\end{tabular}

\section{Strains and media}

A complete list of the yeast strains created and used in this work is presented in Table 2.

Growth and handling of $S$. cerevisiae were done by standard techniques. Yeast strains were transformed with the appropriate plasmids as described by Villa et al. (1998). For induction experiments, galactose at a final concentration of $2 \%$ was directly added to yeast cultures grown in nonrepressive medium $(2 \%$ raffinose and $0.08 \%$ glucose). Aliquots of $15 \mathrm{~mL}$ were removed before and $1.5 \mathrm{~h}$ and $3 \mathrm{~h}$ after the induction.

\section{Plasmid construction}

The ASC1 gene (from positions +1 to + 1233 with respect to the ATG codon) was amplified by PCR and then cloned into the BamHI and EcoRI sites of the p413GAL1 plasmid to produce the construct GAL/ U24HG. BamHI-EcoRI ASC1 fragments were recovered and then cloned into the BamHI and EcoRI sites of Bluescript plasmid to produce pBS-ASC1. The introduction of the TAG sequence between the $C^{\prime}$ and $\mathrm{D}^{\prime}$ boxes of the U24 snoRNA was achieved by inverse PCR with oligonucleotides U24TAG-f and U24TAG-b (pBSASC1/U24TAG). Subsequently, ASC1/ U24TAG fragments were inserted into the BamHI-EcoRI sites of p413GAL1 to produce the plasmid pGAL-U24TAG. The elimination of $40 \mathrm{nt}$ between the $3^{\prime}$ end of the U24 snoRNA and the branch site and between the $5^{\prime}$-splice site and the $5^{\prime}$ end of the U24 snoRNA was achieved by inverse PCR on the pBS-ASC1-U24TAG plasmid using oligonucleotides U24bpSHORT-f and U24bpSHORT-b, and U245'SHORT-f and U245'SHORT-b, to produce pBSU24bp-44 and pBSU24-5'-39, respectively. The insertion of $40 \mathrm{nt}$ between the $3^{\prime}$ end of the U24 snoRNA and the branch site was obtained by inverse PCR on pBS-ASC1/U24TAG utilizing oligonucleotides U24bpLONG-f and U24bpLONG-b to produce plasmid pBSU24bp-124. BamHI-EcoRI U24bp-44, BamHI-EcoRI U24-5'-39, and BamHIEcoRI U24bp-124 fragments were recovered and then cloned into p413GAL1 to produce plasmids pGAL-U24bp-44, pGAL-U24-5' 39, and pGAL-U24bp-124. The C-box of the U24 was mutated by inverse PCR using oligonucleotides U24C-mut-f and U24Cmut-b, obtaining pBSU24bC; this construct was further shortened using U24bpSHORT-b and U24bpSHORT-f oligonucleotides to produce pBSU24bC-BP-44. Subsequently, BamHI-EcoRI fragments were inserted into the pGAl413plasmid to produce pGALU24bC and pGALU24bC-BP-44. The pBSU24bp-44 plasmid was lengthened by insertion of 40 base pairs (bp) between the $\mathrm{D}^{\prime}$ and $\mathrm{C}^{\prime}$ boxes in the U24 coding region by inverse PCR, using U24sno-long-b and U24sno-long-f oligonucleotides. The obtained construct, pBSU24bp-44+40, was digested by BamHI and EcoRI enzymes and then cloned in the pGA413 plasmid to produce pGALU24bp-44+40. The U24bpSHORT-+40B and SHORT-f oligonucleotides were used to generate pBSU24BP-71. BamHI-EcoRI U24bp-71 fragments were recovered and then cloned into the p413GAL1 plasmid to produce plasmid pGAL-U24BP-71.

Part of the EF $\beta-1$ gene (from positions -24 to +524 with respect to the ATG codon) was amplified by PCR and then cloned 
TABLE 2. Strains used in this study

\begin{tabular}{|c|c|c|c|}
\hline Strain & Genotype & Plasmid & Reference \\
\hline yAF1 & $\begin{array}{l}\text { MAT } \alpha, \operatorname{trp} 1 . \Delta, \text { his3. } \Delta, \text { ura3.52, lys } 2.801, \text { ade2.01, } \\
\text { URA3::U24, NOP1::TAP::TRP1 }\end{array}$ & & A. Fatica (unpubl.) \\
\hline yAF2 & $\begin{array}{l}\text { MAT } \alpha, \operatorname{trp} 1 . \Delta, \text { his3. } \Delta, \text { ura3.52, lys } 2.801, \text { ade2.01, } \\
\text { URA3::U24, NOP56::TAP::TRP1 }\end{array}$ & & A. Fatica (unpubl.) \\
\hline yAF3 & $\begin{array}{l}\text { MAT } \alpha, \operatorname{trp} 1 . \Delta, \text { his3. } \Delta, \text { ura3.52, lys } 2.801, \text { ade2.01, } \\
\text { URA3::U24, NOP58::TAP::TRP1 }\end{array}$ & & A. Fatica (unpubl.) \\
\hline ySV 10 & $\begin{array}{l}\text { MAT } \alpha, \operatorname{trp} 1 . \Delta, \text { his3. } \Delta, \text { ura3.52, lys } 2.801, \text { ade2.01, } \\
\text { URA3::U24, NOP58::TAP::TRP1 }\end{array}$ & pGAL-U24TAG[URA3] & This study \\
\hline ySV 11 & $\begin{array}{l}\text { MAT } \alpha, \operatorname{trp} 1 . \Delta, \text { his3. } \Delta, \text { ura3.52, lys } 2.801, \text { ade2.01, } \\
\text { URA3::U24, NOP58::TAP::TRP1 }\end{array}$ & pGAL-U24BP-44[URA3] & This study \\
\hline ySV 12 & $\begin{array}{l}\text { MAT } \alpha, \operatorname{trp} 1 . \Delta, \text { his3. } \Delta, \text { ura3.52, lys } 2.801, \text { ade2.01, } \\
\text { URA3::U24, NOP58::TAP::TRP1 }\end{array}$ & pGAL-U24-5'-39[URA3] & This study \\
\hline ySV 13 & $\begin{array}{l}\text { MAT } \alpha, \operatorname{trp} 1 . \Delta, \text { his3. } \Delta, \text { ura3.52, lys } 2.801 \text {, ade2.01, } \\
\text { URA3::U24, NOP58::TAP::TRPI }\end{array}$ & pGAL-U24BP-124[URA3] & This study \\
\hline ySV 14 & $\begin{array}{l}\text { MAT } \alpha, \operatorname{trp} 1 . \Delta, \text { his3. } \Delta, \text { ura3.52, lys } 2.801, \text { ade2.01, } \\
\text { URA3::U24, NOP58::TAP::TRP1 }\end{array}$ & pGAL-U24-bC[URA3] & This study \\
\hline ySV 15 & $\begin{array}{l}\text { MAT } \alpha, \operatorname{trp} 1 . \Delta, \text { his3. } \Delta, \text { ura3.52, lys } 2.801, \text { ade2.01, } \\
\text { URA3::U24, NOP58::TAP::TRP1 }\end{array}$ & pGAL-U24-bC-BP-44[URA3] & This study \\
\hline ySV 16 & $\begin{array}{l}\text { MAT } \alpha, \operatorname{trp} 1 . \Delta, \text { his3. } \Delta, \text { ura3.52, lys } 2.801, \text { ade2.01, } \\
\text { URA3::U24, NOP58::TAP::TRP1 }\end{array}$ & pGAL-U24-bp-44+40[URA3] & This study \\
\hline ySV17 & $\begin{array}{l}\text { MAT } \alpha, \operatorname{trp} 1 . \Delta, \text { his3. } \Delta, \text { ura3.52, lys } 2.801 \text {, ade2.01, } \\
\text { URA3::U24, NOP58::TAP::TRP1 }\end{array}$ & pGAL-U24-BP-71[URA3] & This study \\
\hline W303-1B & MATa, ura3-1, trp1-1, ade2-1, leu2-3, 112, his3-11, 15 & & Amrani et al. (1997) \\
\hline yVDC 10 & MATa, ura3-1, trp1-1, ade2-1, leu2-3, 112, his3-11, 15 & pGALU18WT [URA3] & This study \\
\hline yVDC 11 & MATa, ura3-1, trp1-1, ade2-1, leu2-3, 112, his3-11, 15 & pGALU18BP-71 [URA3] & This study \\
\hline yVDC 12 & MATa, ura3-1, trp1-1, ade2-1, leu2-3, 112, his3-11, 15 & pGALU18BP-45 [URA3] & This study \\
\hline yVDC 13 & MATa, ura3-1, trp1-1, ade2-1, leu2-3, 112, his3-11, 15 & pGALU18BP-151[URA3] & This study \\
\hline yVDC 14 & MATa, ura3-1, trp1-1, ade2-1, leu2-3, 112, his3-11, 15 & pGALU18- $\Delta$ STEM[URA3] & This study \\
\hline yVDC 15 & MATa, ura3-1, trp1-1, ade2-1, leu2-3, 112, his3-11, 15 & pGALU18- $\triangle$ STEM-BP-43 & This study \\
\hline yVDC 16 & MATa, ura3-1, trp1-1, ade2-1, leu2-3, 112, his3-11, 15 & pGAL1U18-5'-C5[URA3] & This study \\
\hline yVDC 17 & MATa, ura3-1, trp1-1, ade2-1, leu2-3, 112, his3-11, 15 & pGAL1U18-5'-C5-BP-71[URA3] & This study \\
\hline yVDC 18 & MATa, ura3-1, trp1-1, ade2-1, leu2-3, 112, his3-11, 15 & pGALU18- $\triangle$ STEM-BP-43-bC[URA3] & This study \\
\hline
\end{tabular}

into the BamHI and XhoI sites of the Bluescript plasmid to produce pBSU18WT. The introduction of a tag into the $3^{\prime}$ sequence of $\mathrm{U} 18$ was obtained by replacement of $20 \mathrm{nt}$ by inverse PCR using oligonucleotides U24TAG- $\mathrm{f}$ and U24TAG-b (the same TAG inserted in the U24 snoRNA). Deletion of 40 nt between the $3^{\prime}$ end of U18 and the branch site of the host intron was achieved by inverse PCR with the oligonucleotides U18bpSHORT-f and U18bpSHORT-b(RS) to produce pBSU18bp-71; this construct was further shortened by $30 \mathrm{nt}$ by inverse PCR with the oligonucleotides U18bpSHORT-b(RS) and U18bpSHORT-BIS-f to produce pBSU18bp-45. Insertion of $40 \mathrm{nt}$ between the U18 snoRNA and the branch site was obtained by inverse PCR with the oligonucleotides U18bpLONG-f and U18bpLONG-b to obtain pBSU18bp-151. Point mutations in the construct pBSU18WT were introduced by inverse PCR with the oligonucleotides U18 $\Delta$ STEM-f and U18- $\Delta$ STEM-b to produce pBSU18- $\Delta$ STEM. Subsequently, this construct was shortened by $71 \mathrm{nt}$ by inverse PCR using the oligonucleotides antiU18 SSTEM-f and U18 $\Delta$ BIS to produce the plasmid pBSU18- $\Delta$ STEM-BP-43. The C-box of this construct was mutated introducing point mutations by U18bC/RS-b and U18bC-f oligonucleotides to produce pBSU18$\triangle$ STEM-BP-43-bC. BamHI-XhoI U18WT, BamHI-XhoI U18BP-71, BamHI-XhoI U18bp-45, BamHI-XhoI U18 $\Delta$ STEM,

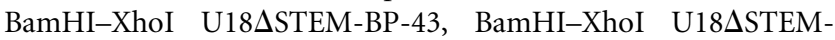

BP-43-bC, and BamHI-XhoI U18BP-151 fragments were recovered and then cloned into p416GAL1 to produce, respectively, pGALU18WT pGALU18BP-71, pGALU18BP-45, pGALU18BP151, pGALU18- $\Delta$ STEM, pGALU18- $\Delta$ STEMBP-43, and pGALU18$\triangle$ STEMBP-43-bC. A point mutation was introduced at the $5^{\prime}$ splice (Villa et al. 1998) to produce pGAL1U18-5'-C5. This construct was subsequently shortened between the $3^{\prime}$ end of U18 and the branch site by inverse PCR with the oligonucleotides U18bpSHORT-f and U18bpSHORT-b(RS) to produce pGALU185'-C5-bp71.

\section{RNA analysis}

RNA was extracted from exponentially growing cultures of S. cerevisiae by the hot-phenol method as previously described by Schmitt et al. (1990).

RNA concentrations were calibrated by adsorbance at $260 \mathrm{~nm}$ and normalized by hybridization with an snR190-specific oligonucleotide. For Northern blot analysis, $5 \mu \mathrm{g}$ of total RNA was run on $6 \%$ polyacrylamide- $7 \mathrm{M}$ urea gels and electrotransferred at $4{ }^{\circ} \mathrm{C}$ to Amersham Hybond- $\mathrm{N}^{+}$filters in $0.5 \times$ TBE buffer for $16 \mathrm{~h}$ at $10 \mathrm{~V}$. Hybridizations were carried out under standard conditions, and $10 \mathrm{pmol}$ of each oligonucleotide was routinely $5^{\prime}$-end labeled with $25 \mu \mathrm{Ci}$ of $\left[\gamma^{-32} \mathrm{P}\right] \mathrm{ATP}$. 


\section{Chromatin immunoprecipitation (ChIP)}

yAF1, yAF2, yAF3, ySV10, and ySV14 strains were grown on $\mathrm{OD}_{600}$ of $0.6-0.8$ and processed essentially as previously described by Komarnitsky et al. (2000). The chromatin preparation was incubated overnight at $4^{\circ} \mathrm{C}$ with rabbit IgG-agarose beads (Sigma) pre-washed in TE buffer. The immunoprecipitate was washed with $275-500 \mathrm{mM} \mathrm{NaCl}$, and recovered and input chromatin were de-cross-linked and amplified by PCR as already described by Komarnitsky et al. (2000).

All primers were designed as 24 mers with $50 \%$ GC content. Their location covers the positions indicated in Figure 6 by the underscored "a," "b," "c," "d," and "e" above the schematic diagrams of EF1- $\beta$ and Asc1 genes; sequences of primers are reported in Table $1 .\left[{ }^{32} \mathrm{P}\right] \mathrm{dATP}$ was added to the PCR reaction $(1 \mu \mathrm{Ci} / 12.5 \mu \mathrm{L})$. ChIP results were quantified as described by Nedea et al. (2003): PCR signals were analyzed by PhosphorImager and ImageQuant software (Molecular Dynamics) and normalized for amplification efficiency and subtraction of the background. Each value in the histogram is the average of the signals of five PCR reactions performed on five different preparations of immunoprecipitated DNA.

\section{ACKNOWLEDGMENTS}

We are grateful to Monica Ballarino and Francesco Chiani for helpful suggestions on ChIP analysis. This work was partially supported by grants from MURST (FIRB-p.n. RBNE015MPB and RBNE01KXC9, PRIN and "Centro di eccellenza BEMM”).

Received August 3, 2006; accepted October 11, 2006.

\section{REFERENCES}

Ares Jr., M. and Proudfoot, N.J. 2006. The Spanish connection: Transcription and mRNA processing get even closer. Cell 120: 163-166.

Amrani, N., Minet, M., Le Gouar, M., Lacroute, F., and Wyers, F. 1997. Yeast Pab1 interacts with Rna15 and participates in the control of the poly(A) tail length in vitro. Mol. Cell. Biol. 17: 3694-3701.

Ballarino, M., Morlando, M., Pagano, F., Fatica, A., and Bozzoni, I. 2005. The cotranscriptional assembly of snoRNPs controls the biosynthesis of H/ACA snoRNAs in Saccharomyces cerevisiae. Mol. Cell. Biol. 25: 5396-5403.

Cahill, N.M., Friend, K., Speckmann, W., Li, Z.H., Terns, R.M., Terns, M.P., and Steitz, J.A. 2002. Site-specific cross-linking analyses reveal an asymmetric protein distribution for a box C/D snoRNP. EMBO J. 21: 3816-3828.

Cavaille, J., Nicoloso, M., and Bachellerie, J.P. 1996. Targeted ribose methylation of RNA in vivo directed by tailored antisense RNA guides. Nature 383: 732-735.

Filipowicz, W. and Pogacic, V. 2002. Biogenesis of small nucleolar ribonucleoproteins. Curr. Opin. Cell Biol. 14: 319-327.

Fragapane, P., Prislei, S., Michienzi, A., Caffarelli, E., and Bozzoni, I. 1993. A novel small nucleolar (U16) is encoded inside a ribosomal protein intron and originates by processing of the pre-mRNA. EMBO J. 12: 2921-2928.

Galardi, S., Fatica, A., Bachi, A., Scaloni, A., Presutti, C., and Bozzoni, I. 2002. Purified box C/D snoRNPs are able to reproduce site-specific 2'-O-methylation of target RNA in vitro. Mol. Cell. Biol. 22: 6663-6668.
Ganot, P., Bortolin, M.L., and Kiss, T. 1997. Site-specific pseudouridine formation in preribosomal RNA is guided by small nucleolar RNAs. Cell 89: 799-809.

Gautier, T., Berges, T., Tollervey, D., and Hurt, E. 1997. Nucleolar KKE/D repeat proteins Nop56p and Nop58p interact with Nop1p and are required for ribosome biogenesis. Mol. Cell. Biol. 17: 7088-7098.

Giorgi, C., Fatica, A., Nagel, R., and Bozzoni, I. 2001. Release of U18 snoRNA from its host intron requires interaction of Nop1p with the Rntlp endonuclease. EMBO J. 20: 6856-6865.

Goguel, V. and Rosbash, M. 1993. Splice site choice and splicing effeciency are positively influenced by pre-mRNA intramolecular base pairing in yeast. Cell 72: 893-901.

Hirose, T. and Steitz, J.A. 2001. Position within the host intron is critical for efficient processing of box C/D snoRNAs in mammalian cells. Proc. Natl. Acad. Sci. 98: 12914-12919.

Hirose, T., Shu, M., and Steitz, J.A. 2003. Splicing-dependent and -independent modes of assembly for intron-encoded box $\mathrm{C} / \mathrm{D}$ snoRNPs in mammals. Mol. Cell 12: 113-123.

Hirose, T., Ideue, T., Nagai, M., Hagiwara, M., Shu, M.D., and Steitz, J.A. 2006. A spliceosomal intron binding protein, IBP160, links position-dependent assembly of intron-encoded box C/D snoRNP to pre-mRNA splicing. Mol. Cell 23: 673-684.

Howe, K.J. and Ares Jr., M. 1997. Intron self-complementarity enforces exon inclusion in a yeast pre-mRNA. Proc. Natl. Acad. Sci. 94: 12467-12472.

Kiss, T. 2001. Small nucleolar RNA-guided post-transcriptional modification of cellular RNAs. EMBO J. 20: 3617-3622.

Kiss-Laszlo, Z., Henry, Y., Bachellerie, J.P., Caizergues-Ferrer, M., and Kiss, T. 1996. Site-specific ribose methylation of preribosomal RNA: A novel function for small nucleolar RNAs. Cell 85: 1077-1088.

Komarnitsky, P., Cho, E.J., and Buratowski, S. 2000. Different phosphorylated forms of RNA polymerase II and associated mRNA processing factors during transcription. Genes \& Dev. 14: 2452-2460.

Kotovic, K.M., Lockshon, D., Boric, L., and Neugebauer, K.M. 2003. Cotranscriptional recruitment of the U1 snRNP to intron-containing genes in yeast. Mol. Cell. Biol. 23: 5768-5779.

Lafontaine, D.L. and Tollervey, D. 1999. Nop58p is a common component of the box C-D snoRNPs that is required for snoRNA stability. RNA 5: 455-467.

Laneve, P., Altieri, F., Fiori, M.F., Scaloni, A., Bozzoni, I., and Caffarelli, E. 2003. Purification, cloning, and characterization of XendoU, a novel endoribonuclease involved in processing of intron-encoded small nucleolar RNAs in Xenopus laevis. J. Biol. Chem. 278: 13026-13032.

Moore, M.J., Query, C.C., and Sharp, P.A. 1993. Splicing of precursors to mRNA by the spliceosome (Review). In The RNA world (eds. R.F. Gesteland and J.F. Atkins), pp. 303-358. Cold Spring Harbor Laboratory Press, Cold Spring Harbor, NY.

Nedea, E., He, X., Kim, M., Pootoolal, J., Zhong, G., Canadien, V., Hughes, T., Buratowski, S., Moore, C.L., and Greenblatt, J. 2003. Organization and function of APT, a subcomplex of the yeast cleavage and polyadenylation factor involved in the formation of mRNA and snoRNA 30 ends. J. Biol. Chem. 278: 33000-33010.

Ni, J., Tien, A.L., and Fournier, M.J. 1997. Small nucleolar RNAs direct site-specific synthesis of pseudouridine in ribosomal RNA. Cell 89: $565-573$.

Nottrott, S., Hartmuth, K., Fabrizio, P., Urlaub, H., Vidovic, I., Ficner, R., and Luhrmann, R. 1999. Functional interaction of a novel $15.5 \mathrm{kD}$ (U4/U6, U5) tri-snRNP protein with the $5^{\prime}$ stemloop of U4 snRNA. EMBO J. 18: 6119-6133.

Richard, P. and Kiss, M.A. 2006. Integrating of snoRNP assembly with mRNA biogenesis. EMBO Rep. 7: 590-592.

Richard, P., Kiss, M.A., Darzacq, X., and Kiss, T. 2006. Cotranscriptional recognition of human intronic box H/ACA snoRNAs occurs in a splicing-independent manner. Mol. Cell. Biol. 26: 2540-2549. 
Schmitt, M.E., Brown, T.A., and Trumpower, B.L. 1990. A rapid simple method for preparation of RNA from Saccharomyces cerevisiae. Nucleic Acids Res. 18: 3091-3092.

Tollervey, D. and Kiss, T. 1997. Function and synthesis of small nucleolar RNAs. Curr. Opin. Cell Biol. 9: 337-342.

Tyc, K. and Steitz, J.A. 1989. U3, U8 and U13 comprise a new class of mammalian snRNPs localized in the cell nucleolus. EMBO J. 8: 3113-3119.

Tycowski, K.T., Shu, M.D., and Steitz, J.A. 1993. A small nucleolar RNA is processed from an intron of the human gene encoding ribosomal protein S3. Genes \& Dev. 7: 1176-1190.

Villa, T., Ceradini, F., Presutti, C., and Bozzoni, I. 1998. Processing of the intron-encoded U18 small nucleolar RNA in the yeast Saccharomyces cerevisiae relies on both exo- and endonucleolytic activities. Mol. Cell. Biol. 18: 3376-3383.
Villa, T., Ceradini, F., and Bozzoni, I. 2000. Identification of a novel element required for processing of intron-encoded box C/D small nucleolar RNAs. Mol. Cell. Biol. 20: 1311-1320.

Watkins, N.J., Leverette, R.D., Xia, L., Andrews, M.T., and Maxwell, S. 1996. Element essential for processing intronic U14 snoRNA are located at the termini of the mature snoRNA sequence and include conserved nucleotide box C and D. RNA 2: 118-133.

Watkins, N.J., Dickmanns, A., and Lührmann, R. 2002. Conserved stem II of the box C/D motif is essential for nucleolar localization and is required, along with the $15.5 \mathrm{~K}$ protein, for the hierarchical assembly of the box C/D snoRNP. Mol. Cell. Biol. 22: 8342-8352.

Weinstein, L.B. and Steitz, J.A. 1999. Guided tours: From precursor snoRNA to functional snoRNP. Curr. Opin. Cell Biol. 11: $378-384$. 

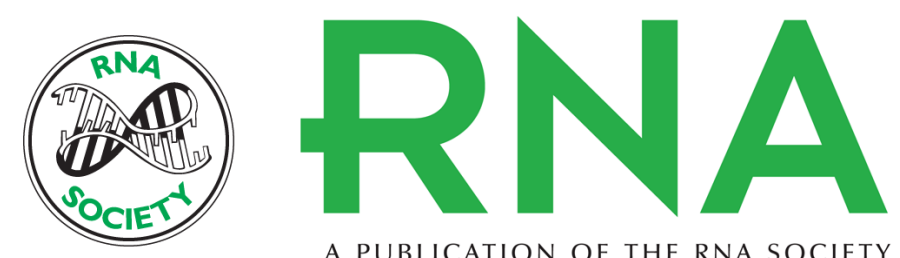

A PUBLICATION OF THE RNA SOCIETY

\section{The position of yeast snoRNA-coding regions within host introns is essential for their biosynthesis and for efficient splicing of the host pre-mRNA}

Sara Vincenti, Valentina De Chiara, Irene Bozzoni, et al.

RNA 2007 13: 138-150 originally published online November 29, 2006

Access the most recent version at doi:10.1261/rna.251907

References This article cites 35 articles, 21 of which can be accessed free at:

http://rnajournal.cshlp.org/content/13/1/138.full.html\#ref-list-1

License

Email Alerting Receive free email alerts when new articles cite this article - sign up in the box at the Service top right corner of the article or click here.

To subscribe to RNA go to:

http://rnajournal.cshlp.org/subscriptions 